\title{
Can GSTMI and GSTTI polymorphisms predict clinical outcomes of chemotherapy in gastric and colorectal cancers? A result based on the previous
}

\section{reports}

\author{
This article was published in the following Dove Press journal: \\ OncoTargets and Therapy \\ 21 June 2016 \\ Number of times this article has been viewed
}

\begin{abstract}
Haixia Liu',*
Wei Shi ${ }^{2, *}$

Lianli Zhao ${ }^{3}$

Dianlu Dai ${ }^{4}$

Jinghua $\mathrm{Gao}^{5}$

Xiangjun Kong ${ }^{6}$

'Department of Ultrasound, ${ }^{2}$ Office of Medical Statistics, ${ }^{3}$ Human Resource

Department, ${ }^{4}$ Department of Surgical

Oncology, ${ }^{5}$ Department of Medical

Oncology, ${ }^{6}$ Central Laboratory,

Cangzhou Central Hospital, Yunhe

District, Cangzhou, People's Republic

of China
\end{abstract}

*These authors contributed equally to this study and should be considered cofirst authors
Correspondence: Wei Shi

Office of Medical Statistics Cangzhou

Central Hospital, No 16 Xinhua West

Road, Yunhe District, Cangzhou 06I00I,

People's Republic of China

Tel +86 I36 63178789

Email drweishi@I63.com

Lianli Zhao

Human Resource Department, Cangzhou Central Hospital, No 16 Xinhua West

Road, Yunhe District, Cangzhou 06I00I,

People's Republic of China

Tel +86 I393272 16I8

Email drllzhao@I63.com
Background: Gastric and colorectal cancers remain the major causes of cancer-related death. Although chemotherapy improves the prognosis of the patients with gastrointestinal cancers, some patients do not benefit from therapy and are exposed to the adverse effects. The polymorphisms in genes including GSTM1 and GSTT1 have been explored to predict therapeutic efficacy; however, the results were inconsistent and inconclusive.

Materials and methods: A systematic review and meta-analysis was performed by searching relevant studies about the association between the GSTM1 and GSTT1 polymorphisms and chemotherapy efficacy in gastrointestinal cancers in databases such as PubMed, EMBASE, Web of Science, Chinese National Knowledge Infrastructure, and Wanfang database up to January 10, 2016. Subgroup analyses were also performed according to ethnicity, cancer type, evaluation criteria, study type, chemotherapy type, and age.

Results: A total of 19 articles containing 3,217 cases were finally included. Overall analysis suggested that no significance was found between overall toxicity, neurotoxicity, neutropenia, gastrointestinal toxicity, tumor response, and progression-free survival, and the polymorphisms in GSTM1 and GSTT1, while GSTM1 polymorphism associated with overall survival (OS; hazard ratio $=1.213,95 \%$ confidence interval $=1.060-1.388, P=0.005$ ). Subgroup analyses suggested that neurotoxicity was associated with GSTM1 polymorphism in the Asian population, neutropenia was associated with GSTM1 polymorphism in palliative chemotherapy and older patients (mean age $>60$ years), and tumor response was associated with GSTT1 polymorphism in gastric cancer and responders defined by complete and partial responses. Meanwhile, GSTM1 was associated with OS in Caucasians, Asians, those with colorectal cancer, and patients with mean age $<60$ years. GSTT1 polymorphism was also associated with OS in Caucasians and patients with mean age $>60$ years.

Conclusion: The polymorphisms in GSTM1 and GSTT1 did not associate with the chemotherapy-related toxicity in gastrointestinal cancers, while GSTT1 polymorphism associated with OS, and further well-designed, larger-scale epidemiological studies are needed to validate our results.

Keywords: meta-analysis, polymorphism, gastrointestinal cancer, chemotherapy, GSTT1, GSTM1

\section{Introduction}

Gastric and colorectal cancers remain the major causes of cancer-related death and have bad prognosis to date. ${ }^{1-3}$ Surgery has been the common choice for managing early-stage and advanced gastrointestinal malignancies. Unfortunately, many patients

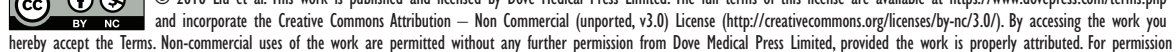
hereby accept the Terms. Non-commercial uses of the work are permitted without any further permission from Dove Medis
for commercial use of this work, please see paragraphs 4.2 and 5 of our Terms (https://www.dovepress.com/terms.php). 
relapse with local recurrence or distant metastasis after surgery. ${ }^{4}$ On the other hand, about $20 \%-30 \%$ patients were diagnosed as having inoperable disease initially. Hence, a systemic therapy is needed for the majority of patients at some point during the course of the disease. Palliative, neoadjuvant, and adjuvant chemotherapy have been widely used for gastrointestinal cancers. ${ }^{5}$

Up to now, 5-fluropyrimidines, oxaliplatin, irinotecan, and monoclonal antibodies such as cetuximab, panitumumab, and bevacizumab are the most common drugs for gastrointestinal cancers in chemotherapy. ${ }^{6}$ Although chemotherapy improves prognosis of the patients with gastrointestinal cancers, some patients do not benefit from the therapy and are exposed to the adverse effects. ${ }^{7,8}$ One major cause of different efficacy resulting from a homologous regimen may be the individual genetic variation in genes associated with detoxification, metabolism, DNA repair, excretion, or transport. ${ }^{9}$

GSTM1 and GSTT1 are members of the glutathione $S$-transferase (GST) family and are involved in the detoxification pathway of a wide variety of electrophiles, including chemotherapeutic agents. A null polymorphism or total gene deletion of the two genes will block the gene activity.

In recent years, a series of studies have been conducted to investigate the associations of GSTM1 and GSTT1 polymorphisms with clinical outcomes of chemotherapy, including toxicities, tumor response, and progression-free survival/ overall survival (PFS/OS) in gastric or colorectal cancer; however, the results were inconsistent and inconclusive. Here, a systematic review and meta-analysis was performed, for the first time, to explore these associations.

\section{Materials and methods Publication search}

A systematic search was performed for published articles on the relationship between glutathione $S$-transferases M1 or T1 polymorphisms and chemotherapy in gastrointestinal cancers using the following search terms: "gastric or stomach or colorectal or colon or rectal," "cancer or tumor or carcinoma," "polymorphism or polymorphisms or variant" "glutathione S-transferase M1 or glutathione S-transferase T1 or GSTM1 or GSTT1," and "chemotherapy" in English databases (PubMed, EMBASE, and Web of Science) with the last search update on January 10, 2016. Two independent authors screened and selected the retrieved articles according to the inclusion and exclusion criteria. The review articles and the references of selected articles were also screened to identify additional eligible studies.

\section{Inclusion and exclusion criteria}

The inclusion criteria were as follows: 1) studies evaluating the relationship between glutathione $S$-transferases M1 or T1 polymorphisms and chemotherapy efficacy including toxicities, tumor response, and/or PFS/OS; 2) studies performed in gastric cancer or colorectal cancer; and 3) studies in which genotype frequency data was specific to clinical features and/or prognosis and could be obtained. Exclusion criteria were as follows: 1) studies including patients with carcinoma other than gastric or colorectal cancers; 2) studies with insufficient or duplicate data; and 3) studies that were not original research articles, such as abstracts, letters, or review articles.

\section{Data extraction}

Two independent authors collected data from all eligible studies in duplicate. A predefined table containing the following terms was used: name of first author, year of publication, country of origin, study type, cancer type, ethnicity cases number, sex, mean age, Eastern Cooperative Oncology Group (ECOG) score, Karnofsky scale, metastatic sites number, disease stage/grade, pre-/postsurgery data, prechemotherapy/-radiotherapy details, responder definition, genotyping method, chemotherapy strategy, chemotherapy type, toxicity type, evaluation criteria, and genotype data. Inconsistency was resolved by discussion.

\section{Statistical analysis}

The crude odds ratios (ORs) and hazard ratios (HRs) and their $95 \%$ confidence intervals (95\% CIs) were calculated to assess the strength of association between GSTM1 or GSTT1 polymorphism and chemotherapy outcomes in gastric and colorectal cancers. The statistical significant level was determined by $Z$-test, with $P$-value less than 0.05 . The heterogeneity was assessed by the chi-square test based on $Q$-statistic test, with a $P$-value $<0.1$ or $P^{2}>50 \%$. If $P>0.1$ and $I^{2}<50 \%$, the pooled OR and $95 \%$ CIs were calculated by the fixed effects model (Mantel-Haenszel method); otherwise, the random-effects model (DerSimonian-Laird method) was used. ${ }^{10}$ Sensitivity analysis was also conducted to evaluate the effect of each study on the combined ORs and HRs by omitting each study in each turn. Besides, subgroup analyses according caner type, ethnicity, chemotherapy type, study type, evaluation criteria, mean age, and responder definition were also performed. Potential publication bias was checked by Begg's funnel plots and Egger's test. ${ }^{11,12}$ Stata 12.0 software (StataCorp, College Station, TX, USA) was used to perform all the analyses. 


\section{Results \\ Study characteristics}

According to the searching strategy and the criteria of inclusion and exclusion, the literature was collected. As shown in Figure 1, a total of 95 documents were initially retrieved, of which 25 were from PubMed, 33 were from EMBASE, and 37 were from Web of Science. After excluding 48 duplicated papers, 12 reviews or meeting abstracts, and 11 irrelevant papers, 24 articles were left for further evaluation. Then, a further 5 papers were excluded because they did not have sufficient data or had overlapping data. Finally, 19 eligible articles containing 3,217 cases were included in the meta-analysis. ${ }^{913-30}$ The characteristics of each included study are listed in the Tables 1 and S1. These 19 articles were published from 2006 to 2014. Of these, 13 studies were performed in Caucasians and six were done in Asians. Eighteen articles reported GSTM1 polymorphism-related data, while 13 articles reported GSTT1 polymorphism.

\section{Meta-analysis results}

\section{Associations of GSTM I and GSTTI polymorphisms} with chemotherapy-related toxicities

Overall, no significance was found between overall toxicity, neurotoxicity, neutropenia, or gastrointestinal toxicity and the polymorphisms in GSTMI and GSTTI (Table 1). Then, subgroup analyses stratified by ethnicity, cancer type, evaluation criteria, study type, chemotherapy type, and mean age were performed to investigate the association of the toxicity with polymorphisms. Unfortunately, there was still no significant association identified between the toxicities and the polymorphisms, except for the neurotoxicity associated with GSTM1 polymorphism in the Asian subgroup ( $\mathrm{OR}=3.361,95 \% \mathrm{CI}=1.324-8.532, P=0.011)$; however, the number of included studies was less $(\mathrm{n}=2)$. Neutropenia associated with GSTM1 polymorphism in palliative chemotherapy $(\mathrm{OR}=1.503,95 \% \mathrm{CI}=1.024-2.208, P=0.038$ ) and elder patients with mean age $>60$ years $(\mathrm{OR}=1.613,95 \%$ $\mathrm{CI}=1.064-2.445, P=0.024$; Figure 2 and Table 2).

\section{Associations of GSTMI and GSTTI polymorphisms with tumor response}

No significant association was identified between polymorphisms in GSTM1 and GSTT1 and tumor response after chemotherapy in gastric and colorectal cancers in overall analysis; however, we observed that patients with GSTT1 null genotype had a trend of lower response rate $(\mathrm{OR}=0.760,95 \% \mathrm{CI}=0.568-1.016, P=0.064$; Figure 2 and Table 3). We also performed subgroup analysis according to ethnicity, cancer type, evaluation criteria, chemotherapy type, mean age, and responder definition, and the results revealed that GSTT1 null genotype was associated with a lower tumor response in patients with gastric cancer $(\mathrm{OR}=0.674,95 \% \mathrm{CI}=0.466-0.974, P=0.036)$ and in responders, as defined by complete and partial response $(\mathrm{CR}+\mathrm{PR} ; \mathrm{OR}=0.730,95 \% \mathrm{CI}=0.535-0.994, P=0.046$; Figure 2 and Table 3 ).

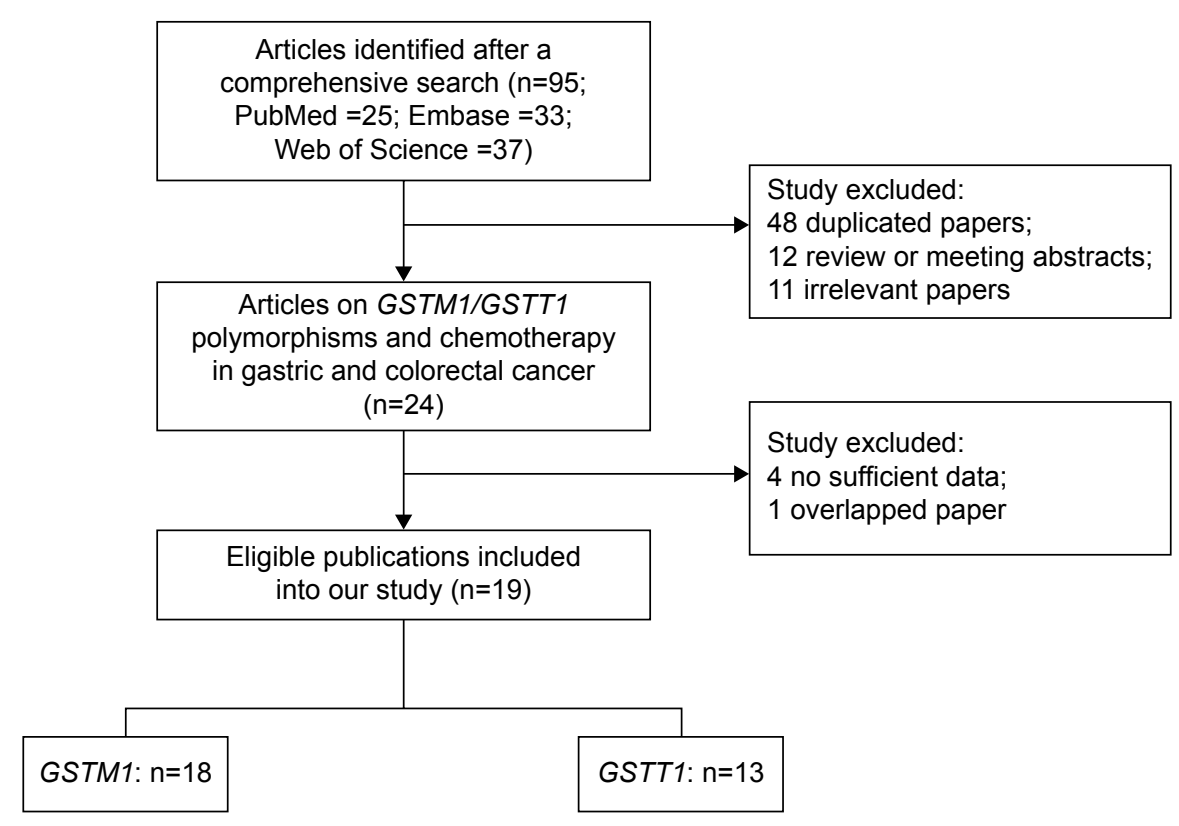

Figure I Flowchart of study selection. 


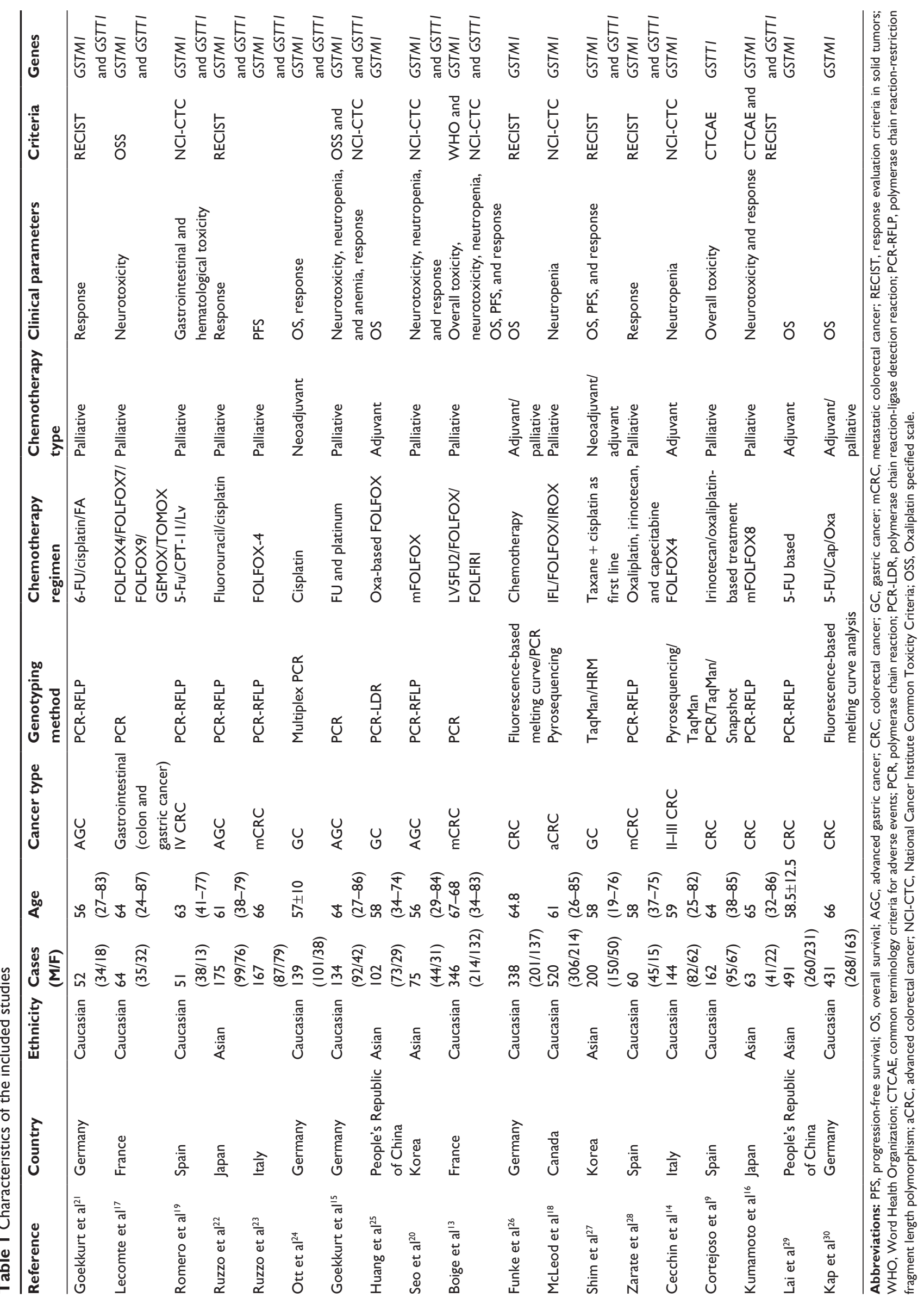




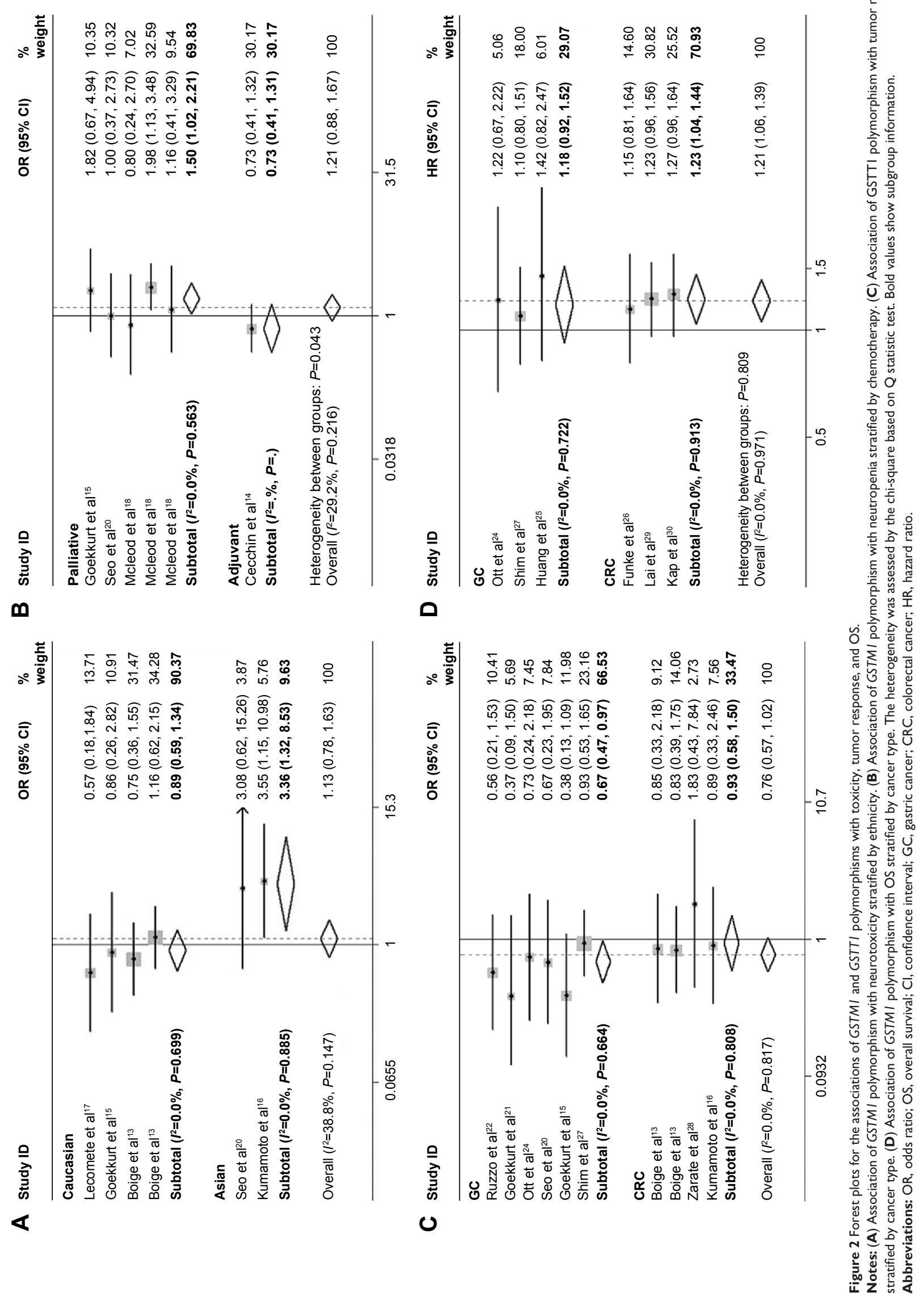


Table 2 Associations of GSTMI and GSTTI polymorphisms with toxicities

\begin{tabular}{|c|c|c|c|c|c|c|c|c|c|c|}
\hline Toxicity & Polymorphism & $\begin{array}{l}\text { Subgroup } \\
\text { analysis }\end{array}$ & $\mathbf{N}$ & OR (95\% Cl) & $P_{\text {OR }}$ & $\mathbf{M}$ & $I^{2}(\%)$ & $\boldsymbol{P}_{\text {Heter }}$ & $\boldsymbol{P}_{\text {Begg }}$ & $P_{\text {Egger }}$ \\
\hline \multirow[t]{3}{*}{ Overall toxicity } & GSTMI (-vs +) & Overall & 2 & $1.109(0.634-1.940)$ & 0.716 & $\mathrm{~F}$ & 0.0 & 0.534 & & \\
\hline & GSTTI (- vs +) & $\mathrm{NCl}-\mathrm{CTC}$ & 2 & $1.432(0.7 \mid 8-2.853)$ & 0.308 & $\mathrm{~F}$ & 1.8 & 0.313 & & \\
\hline & & Overall & 3 & $2.101(0.458-9.646)$ & 0.340 & $\mathrm{~F}$ & 51.9 & 0.125 & 1.000 & 0.900 \\
\hline \multirow[t]{20}{*}{ Neurotoxicity } & GSTMI (-vs +) & Caucasian & 4 & 0.891 (0.592-I.342) & 0.582 & $\mathrm{~F}$ & 0.0 & 0.699 & & \\
\hline & & Asian & 2 & 3.361 ( $(1.324-8.532)$ & 0.011 & $\mathrm{~F}$ & 0.0 & 0.885 & & \\
\hline & & GC & 2 & $1.442(0.579-3.586)$ & 0.432 & $\mathrm{~F}$ & 36.9 & 0.208 & & \\
\hline & & CRC & 3 & $1.298(0.62|-2.7| 4)$ & 0.485 & $\mathrm{R}$ & 61.1 & 0.076 & & \\
\hline & & OSS & 2 & $0.70 \mathrm{I}(0.306-1.608)$ & 0.402 & $\mathrm{~F}$ & 0.0 & 0.632 & & \\
\hline & & $\mathrm{NCl}-\mathrm{CTC}$ & 3 & $1.080(0.692-1.685)$ & 0.734 & $\mathrm{~F}$ & 24.3 & 0.267 & & \\
\hline & & Retrospective & 2 & $\mathrm{I} .436(0.240-8.58 \mathrm{I})$ & 0.691 & $\mathrm{R}$ & 79.4 & 0.028 & & \\
\hline & & Prospective & 4 & I.05। (0.693-I.593) & 0.816 & $\mathrm{~F}$ & 0.0 & 0.433 & & \\
\hline & & Age $(>60)$ & 5 & I.05I (0.7।8-I.538) & 0.798 & $\mathrm{~F}$ & 38.7 & 0.163 & & \\
\hline & & Overall & 6 & $1.129(0.782-1.630)$ & 0.516 & $\mathrm{~F}$ & 38.8 & 0.147 & 0.707 & 0.480 \\
\hline & GSTTI (- vs +) & Caucasian & 4 & $1.252(0.757-2.069)$ & 0.381 & $\mathrm{~F}$ & 0.0 & 0.708 & & \\
\hline & & Asian & 2 & $1.105(0.549-2.225)$ & 0.780 & $\mathrm{~F}$ & 0.0 & 0.706 & & \\
\hline & & GC & 2 & $1.160(0.523-2.575)$ & 0.715 & $\mathrm{~F}$ & 0.0 & 0.779 & & \\
\hline & & CRC & 3 & $1.197(0.713-2.010)$ & 0.496 & $\mathrm{~F}$ & 0.0 & 0.469 & & \\
\hline & & OSS & 2 & I. I I8 (0.406-3.077) & 0.829 & $\mathrm{~F}$ & 0.0 & 0.793 & & \\
\hline & & $\mathrm{NCl}-\mathrm{CTC}$ & 3 & I.28I (0.783-2.094) & 0.324 & $\mathrm{~F}$ & 0.0 & 0.529 & & \\
\hline & & Retrospective & 2 & $1.055(0.455-2.445)$ & 0.900 & $\mathrm{~F}$ & 0.0 & 0.742 & & \\
\hline & & Prospective & 4 & $1.248(0.782-1.992)$ & 0.353 & $\mathrm{~F}$ & 0.0 & 0.708 & & \\
\hline & & Age $(>60)$ & 5 & $1.190(0.755-1.876)$ & 0.454 & $\mathrm{~F}$ & 0.0 & 0.810 & & \\
\hline & & Overall & 6 & $1.200(0.798-1.804)$ & 0.382 & $\mathrm{~F}$ & 0.0 & 0.901 & 0.707 & 0.480 \\
\hline \multirow[t]{8}{*}{ Neutropenia } & GSTMI (-vs +) & Caucasian & 5 & $1.235(0.880-1.734)$ & 0.222 & $\mathrm{~F}$ & 42.2 & 0.140 & & \\
\hline & & GC & 2 & $1.352(0.667-2.740)$ & 0.408 & $\mathrm{~F}$ & 0.0 & 0.408 & & \\
\hline & & CRC & 4 & $1.130(0.642-1.989)$ & 0.673 & $\mathrm{R}$ & 52.1 & 0.100 & & \\
\hline & & Palliative & 5 & $1.503(1.024-2.208)$ & 0.038 & $\mathrm{~F}$ & 0.0 & 0.563 & & \\
\hline & & Age $(<60)$ & 2 & $0.792(0.478-|.3| \mathrm{I})$ & 0.364 & $\mathrm{~F}$ & 0.0 & 0.526 & & \\
\hline & & Age $(>60)$ & 4 & $1.613(1.064-2.445)$ & 0.024 & $\mathrm{~F}$ & 0.0 & 0.590 & & \\
\hline & & Overall & 6 & $1.209(0.877-1.667)$ & 0.247 & $\mathrm{~F}$ & 29.2 & 0.216 & 0.452 & 0.801 \\
\hline & GSTTI (- vs +) & Overall & 2 & I. $167(0.544-2.500)$ & 0.692 & $\mathrm{~F}$ & 0.0 & 0.505 & & \\
\hline \multirow{2}{*}{$\begin{array}{l}\text { Gastrointestinal } \\
\text { toxicity }\end{array}$} & GSTMI (-vs +) & Overall & 2 & $2.378(0.868-6.5 \mathrm{II})$ & 0.092 & $\mathrm{~F}$ & 0.0 & 0.322 & & \\
\hline & GSTTI (- vs +) & Overall & 2 & I. $192(0.5$ I $2-2.777)$ & 0.684 & $\mathrm{~F}$ & 0.0 & 0.771 & & \\
\hline
\end{tabular}

Notes: The heterogeneity was assessed by the chi-square based on Q statistic test. Potential publication bias was checked by Begg's funnel plots and Egger's test. Bold values represent a significant association or presence of the trend.

Abbreviations: $\mathrm{Cl}$, confidence interval; GC, gastric cancer; CRC, colorectal cancer; $\mathrm{NCl}-\mathrm{CTC}, \mathrm{NCl}$ common toxicity criteria; OSS, Oxaliplatin specified scale; $\mathrm{M}$, model; $\mathrm{F}$, fixed model; R, random model.

\section{Associations of GSTMI and GSTTI polymorphisms with PFS and OS}

There was no significant association between polymorphisms of GSTM1 and GSTT1 with PFS. For OS, data of six studies were available to analyze its association with GSTM1 and GSTT1 polymorphisms. After pooling analysis and subgroup analysis stratified by ethnicity, cancer type, and mean age, we found that GSTM1 null type associated with a shorter OS in overall analysis (HR $=1.213,95 \%$ $\mathrm{CI}=1.060-1.388, P=0.005)$ and with subgroups of Caucasian $(\mathrm{HR}=1.222,95 \% \mathrm{CI}=1.000-1.493, P=0.050)$, Asian (HR $=1.205,95 \% \mathrm{CI}=1.004-1.446, P=0.045)$, colorectal cancer $(\mathrm{HR}=1.226,95 \% \mathrm{CI}=1.044-1.438, P=0.013)$, and patients with mean age $<60$ years $(\mathrm{HR}=1.206,95 \%$ $\mathrm{CI}=1.013-1.435, P=0.035)$. GSTT1 polymorphism was associated only with OS in the Caucasian subgroup (HR $=1.299$,
95\% CI $=1.046-1.613, P=0.018)$ and patients with mean age $>60$ years $(\mathrm{HR}=1.370,95 \% \mathrm{CI}=1.063-1.765, P=0.015$; Figure 2 and Table 4).

\section{Sensitivity analysis and publication bias}

Sensitivity analysis was performed to examine the influence of individual studies on the pooled ORs by deleting each study once, and similar results were identified for all analyses. Begg's funnel plot and Egger's test were carried out to assess the publication bias among the included studies for chemotherapy efficacy and polymorphisms in GSTM1 and GSTT1 in gastric and colorectal cancers. Symmetrical funnel plots were obtained (Figure 3). The results showed no evidence of publication bias (Tables 2-4). Sensitivity and publication bias analyses were not performed when the number of included original studies was less than three. 
Table 3 Associations of GSTMI and GSTTI polymorphisms with tumor response

\begin{tabular}{|c|c|c|c|c|c|c|c|c|c|c|}
\hline Polymorphism & Subgroup analysis & $\mathbf{N}$ & OR & $95 \% \mathrm{Cl}$ & $P_{O R}$ & $\mathbf{M}$ & $P^{2}(\%)$ & $\boldsymbol{P}_{\text {Heter }}$ & $P_{\text {Begg }}$ & $\boldsymbol{P}_{\text {Egger }}$ \\
\hline \multirow[t]{13}{*}{ GSTMI - vs + } & Caucasian & 7 & 1.123 & $0.842-1.498$ & 0.429 & $\mathrm{~F}$ & 0.0 & 0.451 & & \\
\hline & Asian & 3 & 1.067 & $0.669-1.700$ & 0.786 & $\mathrm{~F}$ & 0.0 & 0.966 & & \\
\hline & GC & 6 & 1.162 & $0.853-1.585$ & $0.34 I$ & $\mathrm{~F}$ & 0.0 & 0.734 & & \\
\hline & CRC & 5 & 1.021 & $0.684-1.524$ & 0.920 & $\mathrm{~F}$ & 0.0 & 0.411 & & \\
\hline & RECIST & 6 & 1.141 & $0.81 \mathrm{I}-1.604$ & 0.448 & $\mathrm{~F}$ & 0.0 & 0.590 & & \\
\hline & WHO & 2 & 1.126 & $0.706-1.795$ & 0.618 & $\mathrm{~F}$ & 0.0 & 0.391 & & \\
\hline & Others & 2 & 1.005 & $0.586-|.72|$ & 0.987 & $\mathrm{~F}$ & 19.1 & 0.266 & & \\
\hline & Palliative & 8 & 1.094 & $0.823-1.453$ & 0.536 & $\mathrm{~F}$ & 0.0 & 0.613 & & \\
\hline & Neoadjuvant/adjuvant & 2 & 1.148 & $0.707-1.863$ & 0.578 & $\mathrm{~F}$ & 0.0 & 0.499 & & \\
\hline & $<60$ & 5 & 1.039 & $0.669-1.545$ & 0.851 & $\mathrm{~F}$ & 0.0 & 0.603 & & \\
\hline & $>60$ & 5 & 1.152 & $0.844-1.572$ & 0.374 & $\mathrm{~F}$ & 0.0 & 0.558 & & \\
\hline & Responder (CR + PR) & 8 & 1.129 & $0.869-1.467$ & 0.366 & $\mathrm{~F}$ & 0.0 & 0.865 & & \\
\hline & Overall & 10 & 1.107 & $0.867-1.415$ & 0.415 & $\mathrm{~F}$ & 0.0 & 0.753 & 0.474 & 0.448 \\
\hline \multirow[t]{13}{*}{ GSTTI - vs + } & Caucasian & 7 & 0.689 & $0.470-1.009$ & 0.056 & $\mathrm{~F}$ & 0.0 & 0.635 & & \\
\hline & Asian & 3 & 0.873 & $0.557-1.368$ & 0.553 & $\mathrm{~F}$ & 0.0 & 0.865 & & \\
\hline & GC & 6 & 0.674 & $0.466-0.974$ & 0.036 & $\mathrm{~F}$ & 0.0 & 0.664 & & \\
\hline & CRC & 4 & 0.931 & $0.568-1.016$ & 0.064 & $\mathrm{~F}$ & 0.0 & 0.808 & & \\
\hline & RECIST & 6 & 0.813 & $0.558-1.183$ & 0.279 & $\mathrm{~F}$ & 0.0 & 0.651 & & \\
\hline & WHO & 2 & 0.836 & $0.465-1.505$ & 0.551 & $\mathrm{~F}$ & 0.0 & 0.962 & & \\
\hline & Others & 2 & 0.513 & $0.240-1.095$ & 0.085 & $\mathrm{~F}$ & 0.0 & 0.399 & & \\
\hline & Palliative & 8 & 0.705 & $0.494-1.006$ & 0.054 & $\mathrm{~F}$ & 0.0 & 0.716 & & \\
\hline & Neoadjuvant/adjuvant & 2 & 0.884 & $0.534-1.463$ & 0.631 & $\mathrm{~F}$ & 0.0 & 0.695 & & \\
\hline & $<60$ & 5 & 0.842 & $0.558-1.270$ & 0.412 & $\mathrm{~F}$ & 0.0 & 0.594 & & \\
\hline & $>60$ & 5 & 0.688 & $0.456-1.037$ & 0.074 & $\mathrm{~F}$ & 0.0 & 0.724 & & \\
\hline & Responder (CR + PR) & 8 & 0.730 & $0.535-0.994$ & 0.046 & $\mathrm{~F}$ & 0.0 & 0.809 & & \\
\hline & Overall & 10 & 0.760 & $0.568-1.016$ & 0.064 & $\mathrm{~F}$ & 0.0 & 0.817 & 0.592 & 0.383 \\
\hline
\end{tabular}

Notes: The heterogeneity was assessed by the chi-square based on Q statistic test. Potential publication bias was checked by Begg's funnel plots and Egger's test. Bold values represent significant association or presence of the trend.

Abbreviations: RECIST, response evaluation criteria in solid tumors; WHO, response evaluation according to Word Health Organization criteria; OR, odds ratio; $\mathrm{Cl}$, confidence interval; $\mathrm{GC}$, gastric cancer; $\mathrm{CRC}$, colorectal cancer; $\mathrm{CR}$, complete response; PR, partial response; Others: did not report the response evaluation criteria; $M$, model; F, fixed model; $R$, random model.

Table 4 Associations of GSTMI and GSTTI polymorphisms with PFS and OS

\begin{tabular}{|c|c|c|c|c|c|c|c|c|c|c|c|}
\hline PFS/OS & $\begin{array}{l}\text { Comparison } \\
\text { model }\end{array}$ & $\begin{array}{l}\text { Subgroup } \\
\text { analysis }\end{array}$ & $\mathbf{N}$ & HR & $95 \% \mathrm{Cl}$ & $P_{\mathrm{HR}}$ & $M$ & $I^{2}(\%)$ & $\boldsymbol{P}_{\text {Heter }}$ & $P_{\text {Begg }}$ & $P_{\text {Egger }}$ \\
\hline PFS & GSTMI - vs + & Overall & 2 & 0.980 & $0.738-1.301$ & 0.889 & $\mathrm{~F}$ & 0.0 & 1.000 & & \\
\hline \multirow[t]{4}{*}{ PFS } & \multirow[t]{4}{*}{ GSTTI - vs + } & GC & 2 & 1.119 & $0.860-1.457$ & 0.402 & $\mathrm{R}$ & 67.0 & 0.082 & & \\
\hline & & Palliative & 2 & 1.474 & $0.960-2.263$ & 0.076 & $\mathrm{~F}$ & 0.0 & 0.400 & & \\
\hline & & $>60$ & 2 & 1.474 & $0.960-2.263$ & 0.076 & $\mathrm{~F}$ & 0.0 & 0.400 & & \\
\hline & & Overall & 3 & 1.123 & $0.877-1.438$ & 0.359 & $\mathrm{~F}$ & 34.0 & 0.220 & 1.000 & 0.545 \\
\hline \multirow[t]{7}{*}{ OS } & \multirow[t]{7}{*}{ GSTMI - vs + } & Caucasian & 3 & 1.222 & $1.000-1.493$ & 0.050 & $\mathrm{~F}$ & 0.0 & 0.914 & & \\
\hline & & Asian & 3 & 1.205 & I.004-I.446 & 0.045 & $\mathrm{~F}$ & 0.0 & 0.704 & & \\
\hline & & GC & 3 & 1.182 & $0.920-1.517$ & 0.191 & $\mathrm{~F}$ & 0.0 & 0.722 & & \\
\hline & & CRC & 3 & 1.226 & I.044-I.438 & 0.013 & $\mathrm{~F}$ & 0.0 & 0.913 & & \\
\hline & & $<60$ & 4 & I.206 & $1.013-1.435$ & 0.035 & $\mathrm{~F}$ & 0 & 0.876 & & \\
\hline & & $>60$ & 2 & 1.225 & $0.990-|.5| 5$ & 0.062 & $\mathrm{~F}$ & 0 & 0.660 & & \\
\hline & & Overall & 6 & 1.213 & I.060-I.388 & 0.005 & $\mathrm{~F}$ & 0.0 & 0.971 & 1.000 & 0.728 \\
\hline \multirow[t]{8}{*}{ OS } & \multirow[t]{8}{*}{ GSTTI - vs + } & Caucasian & 4 & 1.299 & $1.046-1.613$ & 0.018 & $\mathrm{~F}$ & 0.0 & 0.419 & & \\
\hline & & Asian & 2 & 0.953 & $0.643-1.410$ & 0.808 & $\mathrm{R}$ & 75.0 & 0.046 & & \\
\hline & & GC & 3 & 1.135 & $0.677-1.904$ & 0.631 & $\mathrm{R}$ & 77.2 & 0.012 & & \\
\hline & & CRC & 3 & 1.189 & $0.991-1.427$ & 0.062 & $\mathrm{~F}$ & 0.0 & 0.916 & & \\
\hline & & $\begin{array}{l}\text { Palliative/ } \\
\text { adjuvant }\end{array}$ & 2 & 1.243 & $0.942-1.640$ & 0.099 & $\mathrm{~F}$ & 0.0 & 0.957 & & \\
\hline & & $<60$ & 3 & 0.988 & $0.755-1.293$ & 0.930 & $\mathrm{R}$ & 51.8 & 0.126 & & \\
\hline & & $>60$ & 3 & 1.370 & $1.063-1.765$ & 0.015 & $\mathrm{~F}$ & 4.8 & 0.350 & & \\
\hline & & Overall & 6 & 1.144 & $0.920-1.42 \mid$ & 0.226 & $\mathrm{R}$ & 51.3 & 0.068 & 0.260 & 0.385 \\
\hline
\end{tabular}

Notes: The heterogeneity was assessed by the chi-square based on Q statistic test. Potential publication bias was checked by Begg's funnel plots and Egger's test. Bold values represent significant association or presence of the trend.

Abbreviations: PFS, progression-free survival; OS, overall survival; HR, hazard ratio; Cl, confidence interval; GC, gastric cancer; CRC, colorectal cancer; M, model; F, fixed model; $R$, random model. 
A

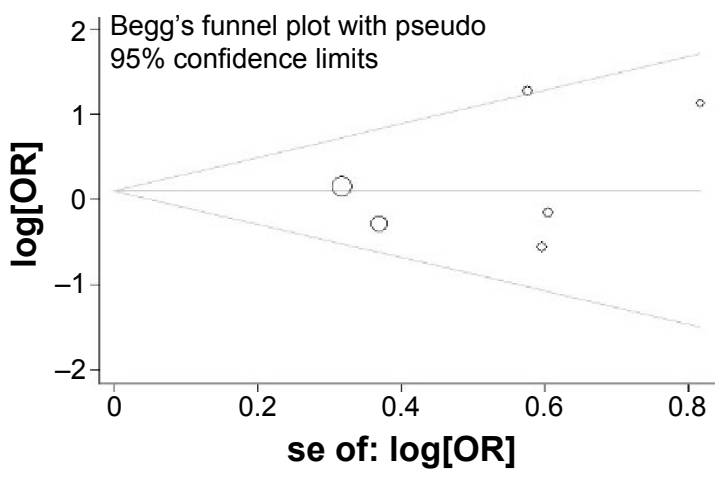

B

Response

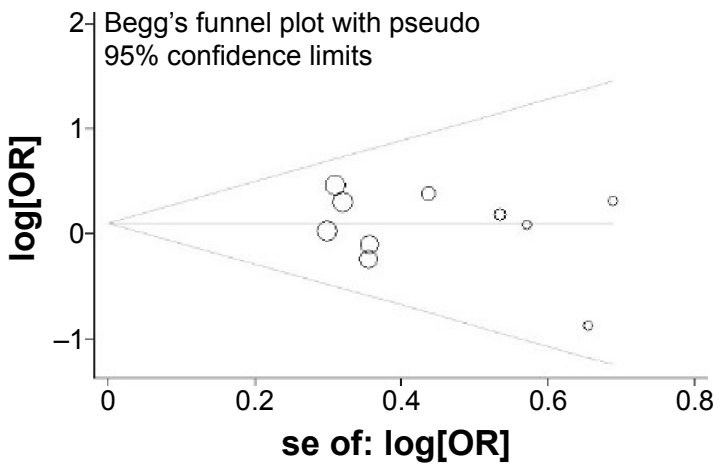

C

OS

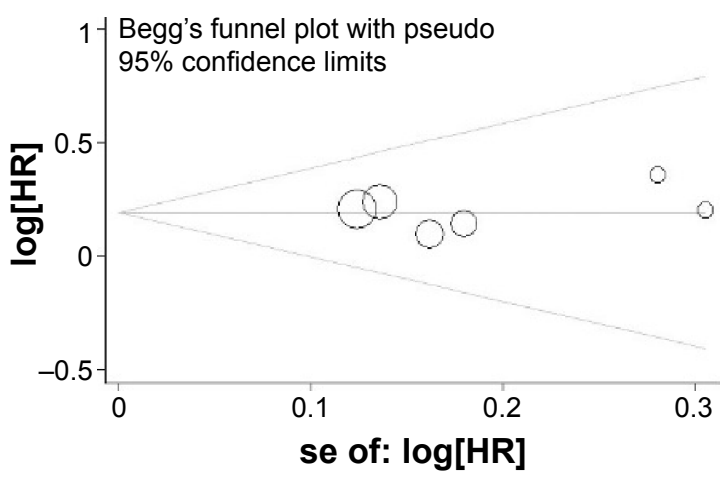

Figure 3 Begg's funnel plot for publication bias analysis for associations of GSTMI polymorphism with neurotoxicity (A), tumor response (B), and OS (C). Abbreviations: OS, overall survival, se, standard error; OR, odds ratio; HR, hazard ratio.

\section{Discussion}

In this meta-analysis study, we pooled 19 publications to explore the associations between GSTM1 and GSTT1 polymorphisms and chemotherapy efficacy in gastric and colorectal cancers.

Chemotherapy has been widely used in the treatment of gastrointestinal malignancies, especially for metastatic or advanced cancers. The most common chemotherapeutic regimens involve the combination of oxaliplatin and irinotecan with fluoropyrimidines. However, the toxicity profile, tumor response, and prognosis of chemotherapy are very heterogeneous, even in a homologous regimen. It is well known that the individual genetic background may be a major cause for the variability of clinical outcomes. In recent years, a series of studies have tried to investigate the predictive value of the polymorphisms in genes involved in detoxification, metabolism, DNA repair, excretion, or transport on chemotherapy of gastrointestinal cancers. ${ }^{22,23}$ For example, polymorphisms in thymidylate synthase have been suggested to determine the cancer cell's sensitivity toward fluoropyrimidines $;^{31,32}$ polymorphism in the methylenetetrahydrofolate reductase gene associates with tumor response to 5-FU monotherapy in patients with advanced colorectal cancer ${ }^{33}$ polymorphism in dihydropyrimidine dehydrogenase associates with toxicity from fluoropymidines treatment; ${ }^{34-38}$ and the mutations within the nucleotide excision repair pathway and the detoxifying GST may be correlated to resistance to platinum compounds. ${ }^{39-41}$ In this study, we investigated the associations of polymorphisms in GSTM1 and GSTT1 with the chemotherapy-related toxicities, tumor response, and prognosis in gastrointestinal cancers for the first time. Pooling analysis revealed no significant association between the polymorphisms and the chemotherapy-related toxicity, tumor response, and prognosis except that GSTM1 null genotype associated with poor OS. Further subgroup analyses suggested that ethnicity, cancer type, chemotherapy type, patient age, and responder definition might have an important influence on the associations. Notably, GSTs are involved in detoxification via direct glutathione conjugation of xenobiotics, and it might be more reasonable that a null genotype, resulting in no enzyme activity, would lead to better tumor response and prognosis after chemotherapy. However, our results suggested that GSTM1 null genotype associated with poor OS, and a trend was also observed between GSTT1 null 
type and poor tumor response and prognosis. The underlying mechanisms might be that the null genotypes of GSTM1 and GSTT1 reduced the GST activity, then elevated the glutathione levels, and finally decreased DNA binding capability of platinum compounds. ${ }^{42-45}$ Besides, GSTM1 and GSTT1 might be involved in other signaling pathways that were critical for the metabolism of the chemotherapeutic drugs, which affected the associations and should be explored in the future.

Although we pooled all the potential studies to investigate the association between the polymorphisms of GSTM1 and GSTT1 and chemotherapy efficacy in gastrointestinal cancers, the publication number and the sample size were still limited. Another limitation of the meta-analysis was the potential instability of the conclusions resulting from the diversity among the original individual studies. In the present meta-analysis, we investigated the effects of the diversity on the result stability and reliability by performing subgroup analysis according to ethnicity, cancer type, toxicity/response criteria, chemotherapy type, study type, age, and responder definition. Additional factors should be taken into consideration as well. As listed in Table S1, we also extracted the following information, sex radio, ECOG scores, Karnofsky scale, metastatic sites number, disease stage, grade, pre-/postsurgery data, and prechemotherapy/radiotherapy details, from original studies. The sex radio (male/female) ranged from 1.13 to 3.00. The ECOG scores, Karnofsky scale, metastatic sites, disease stage, and tumor grade were reported in ten, five, seven, seven, and three studies, respectively. The ECOG scores ranged from 0 to 2 . Four hundred and thirty-three patients had a cancer at single metastatic site and 554 patients had multiple sites of metastasis, respectively. Two hundred and twenty-three patients were in Stage I-II, 589 patients were in Stage III, 590 patients were in Stage IV, 274 patients were in Grade I-II, and 202 patients in Grade II-IV, respectively. There were seven, nine, and one studies reporting previous/postsurgery, prechemotherapy, and preradiotherapy data, respectively. However, these original data were not sufficient for quantitatively evaluating the impact of the diversity among the included studies on the association of the polymorphisms with chemotherapy efficacy. Thus, further well-designed studies with larger sample size and more detailed information should be conducted to confirm the results.

\section{Conclusion}

From the results of the current meta-analysis, it can be observed that the polymorphisms in GSTM1 and GSTT1 were not associated with the chemotherapy-related toxicities, tumor response, and prognosis in gastrointestinal cancers, except for GSTM1 polymorphism being associated with OS. Subgroup analyses suggested that GSTM1 polymorphism might be associated with neurotoxicity in Asians, with neutropenia in palliative chemotherapy and elder patients, and with OS in Caucasians, Asians, and those with colorectal cancer. GSTT1 might be associated with tumor response in gastric cancer and with OS in Caucasians and elder patients.

\section{Acknowledgments}

This study was supported by the grant of Application Value of Type M Color Echocardiography Technology in Evaluation of Right Ventricular Diastolic Function of Umbilical Fetus (number 141302115).

\section{Disclosure}

The authors report no conflicts of interests in this work.

\section{References}

1. Jemal A, Siegel R, Ward E, et al. Cancer statistics, 2008. CA Cancer J Clin. 2008;58(2):71-96.

2. Siegel R, Ma J, Zou Z, Jemal A. Cancer statistics, 2014. CA Cancer J Clin. 2014;64(1):9-29.

3. Kamangar F, Dores GM, Anderson WF. Patterns of cancer incidence, mortality, and prevalence across five continents: defining priorities to reduce cancer disparities in different geographic regions of the world. J Clin Oncol. 2006;24(14):2137-2150.

4. Macdonald JS. Treatment of localized gastric cancer. Semin Oncol. 2004;31(4):566-573.

5. Wagner AD, Grothe W, Haerting J, Kleber G, Grothey A, Fleig WE. Chemotherapy in advanced gastric cancer: a systematic review and meta-analysis based on aggregate data. J Clin Oncol. 2006;24(18): 2903-2909.

6. Wohrer SS, Raderer M, Hejna M. Palliative chemotherapy for advanced gastric cancer. Ann Oncol. 2004;15(11):1585-1595.

7. Chua W, Kho PS, Moore MM, Charles KA, Clarke SJ. Clinical, laboratory and molecular factors predicting chemotherapy efficacy and toxicity in colorectal cancer. Crit Rev Oncol Hematol. 2011;79(3):224-250.

8. Fuchs CS, Moore MR, Harker G, Villa L, Rinaldi D, Hecht JR. Phase III comparison of two irinotecan dosing regimens in second-line therapy of metastatic colorectal cancer. J Clin Oncol. 2003;21(5):807-814.

9. Cortejoso L, Lopez-Fernandez LA. Pharmacogenetic markers of toxicity for chemotherapy in colorectal cancer patients. Pharmacogenomics. 2012;13(10):1173-1191.

10. DerSimonian R, Laird N. Meta-analysis in clinical trials. Control Clin Trials. 1986;7:177-188.

11. Begg CB, Mazumdar M. Operating characteristics of a rank correlation test for publication bias. Biometrics. 1994;50(4):1088-1101.

12. Egger M, Davey Smith G, Schneider M, Minder C. Bias in meta-analysis detected by a simple, graphical test. BMJ. 1997;315(7109):629-634.

13. Boige V, Mendiboure J, Pignon JP, et al. Pharmacogenetic assessment of toxicity and outcome in patients with metastatic colorectal cancer treated with LV5FU2, FOLFOX, and FOLFIRI: FFCD 2000-05. J Clin Oncol. 2010;28(15):2556-2564.

14. Cecchin E, D'Andrea M, Lonardi S, et al. A prospective validation pharmacogenomic study in the adjuvant setting of colorectal cancer patients treated with the 5-fluorouracil/leucovorin/oxaliplatin (FOLFOX4) regimen. Pharmacogenomics J. 2013;13(5):403-409. 
15. Goekkurt E, Al-Batran SE, Hartmann JT, et al. Pharmacogenetic analyses of a phase III trial in metastatic gastroesophageal adenocarcinoma with fluorouracil and leucovorin plus either oxaliplatin or cisplatin: a study of the arbeitsgemeinschaft internistische onkologie. J Clin Oncol. 2009;27(17):2863-2873.

16. Kumamoto K, Ishibashi K, Okada N, et al. Polymorphisms of GSTP1, ERCC2 and TS-3'UTR are associated with the clinical outcome of mFOLFOX6 in colorectal cancer patients. Oncol Lett. 2013;6(3): 648-654.

17. Lecomte T, Landi B, Beaune P, Laurent-Puig P, Loriot MA. Glutathione S-transferase P1 polymorphism (Ile(105)Val) predicts cumulative neuropathy in patients receiving oxaliplatin-based chemotherapy. Clin Cancer Res. 2006;12(10):3050-3056.

18. McLeod HL, Sargent DJ, Marsh S, et al. Pharmacogenetic predictors of adverse events and response to chemotherapy in metastatic colorectal cancer: results from North American Gastrointestinal Intergroup Trial N9741. J Clin Oncol. 2010;28(20):3227-3233.

19. Romero RZ, Morales R, Garcia F, et al. Potential application of GSTT1null genotype in predicting toxicity associated to 5-fluouracil irinotecan and leucovorin regimen in advanced stage colorectal cancer patients. Oncol Rep. 2006;16(3):497-503.

20. Seo BG, Kwon HC, Oh SY, et al. Comprehensive analysis of excision repair complementation group 1 , glutathione S-transferase, thymidylate synthase and uridine diphosphate glucuronosyl transferase 1A1 polymorphisms predictive for treatment outcome in patients with advanced gastric cancer treated with FOLFOX or FOLFIRI. Oncol Rep. 2009; 22(1):127-136.

21. Goekkurt E, Hoehn S, Wolschke C, et al. Polymorphisms of glutathione S-transferases (GST) and thymidylate synthase (TS) - novel predictors for response and survival in gastric cancer patients. Br J Cancer. 2006;94(2):281-286.

22. Ruzzo A, Graziano F, Kawakami K, et al. Pharmacogenetic profiling and clinical outcome of patients with advanced gastric cancer treated with palliative chemotherapy. J Clin Oncol. 2006;24(12):1883-1891.

23. Ruzzo A, Graziano F, Loupakis F, et al. Pharmacogenetic profiling in patients with advanced colorectal cancer treated with first-line FOLFOX-4 chemotherapy. J Clin Oncol. 2007;25(10):1247-1254.

24. Ott K, Lordick F, Becker K, et al. Glutathione-S-transferase P1, T1 and M1 genetic polymorphisms in neoadjuvant-treated locally advanced gastric cancer: GSTM1-present genotype is associated with better prognosis in completely resected patients. Int J Colorectal Dis. 2008;23(8):773-782.

25. Huang ZH, Hua D, Du X. Polymorphisms in p53, GSTP1 and XRCC1 predict relapse and survival of gastric cancer patients treated with oxaliplatin-based adjuvant chemotherapy. Cancer Chemother Pharmacol. 2009;64(5):1001-1007.

26. Funke S, Timofeeva M, Risch A, et al. Genetic polymorphisms in GST genes and survival of colorectal cancer patients treated with chemotherapy. Pharmacogenomics. 2010;11(1):33-41.

27. Shim HJ, Yun JY, Hwang JE, et al. BRCA1 and XRCC1 polymorphisms associated with survival in advanced gastric cancer treated with taxane and cisplatin. Cancer Sci. 2010;101(5):1247-1254.

28. Zarate R, Rodriguez J, Bandres E, et al. Oxaliplatin, irinotecan and capecitabine as first-line therapy in metastatic colorectal cancer (mCRC): a dose-finding study and pharmacogenomic analysis. $\mathrm{Br} J$ Cancer. 2010;102(6):987-994.

29. Lai C-Y, Hsieh L-L, Sung F-C, et al. Tumor site- and stage-specific associations between allelic variants of glutathione s-transferase and DNArepair genes and overall survival in colorectal cancer patients receiving 5-fluorouracil-based chemotherapy. PloS One. 2013;8(7):e69039.
30. Kap EJ, Richter S, Rudolph A, et al. Genetic variants in the glutathione S-transferase genes and survival in colorectal cancer patients after chemotherapy and differences according to treatment with oxaliplatin. Pharmacogenet Genomics. 2014;24(7):340-347.

31. Cui YH, Liu TS, Zhuang RY, Gao HJ, Li H. Polymorphism of thymidylate synthase gene and chemosensitivity of 5-fluorouracil regimen in metastatic gastrointestinal cancer. J Dig Dis. 2009;10(2):118-123.

32. Arrazubi V, Suarez J, Guerrero D, et al. Prognostic significance of thymidylate synthase polymorphisms in rectal cancer patients treated with neoadjuvant chemoradiotherapy. Colorectal Dis. 2013;15(4): 428-435.

33. Castillo-Fernandez O, Santibanez M, Bauza A, et al. Methylenetetrahydrofolate reductase polymorphism $(677 \mathrm{C}>\mathrm{T})$ predicts long time to progression in metastatic colon cancer treated with 5-fluorouracil and folinic acid. Arch Med Res. 2010;41(6):430-435.

34. Deenen MJ, Tol J, Burylo AM, et al. Relationship between single nucleotide polymorphisms and haplotypes in DPYD and toxicity and efficacy of capecitabine in advanced colorectal cancer. Clin Cancer Res. 2011;17(10):3455-3468.

35. Saif MW. Dihydropyrimidine dehydrogenase gene (DPYD) polymorphism among Caucasian and non-Caucasian patients with 5-FU- and capecitabine-related toxicity using full sequencing of DPYD. Cancer Genomics Proteomics. 2013;10(2):89-92.

36. Loganayagam A, Arenas Hernandez M, Corrigan A, et al. Pharmacogenetic variants in the DPYD, TYMS, CDA and MTHFR genes are clinically significant predictors of fluoropyrimidine toxicity. Br J Cancer. 2013;108(12):2505-2515

37. Froehlich TK, Amstutz U, Aebi S, Joerger M, Largiader CR. Clinical importance of risk variants in the dihydropyrimidine dehydrogenase gene for the prediction of early-onset fluoropyrimidine toxicity. Int J Cancer. 2015;136(3):730-739.

38. Li Q, Liu Y, Zhang HM, et al. Influence of DPYD genetic polymorphisms on 5-fluorouracil toxicities in patients with colorectal cancer: a meta-analysis. Gastroenterol Res Prac. 2014;2014:827989.

39. Huang D, Zhou Y. Nucleotide excision repair gene polymorphisms and prognosis of non-small cell lung cancer patients receiving platinum-based chemotherapy: a meta-analysis based on 44 studies. Biomed Rep. 2014; 2(4):452-462.

40. Qin Q, Zhang C, Yang X, et al. Polymorphisms in XPD gene could predict clinical outcome of platinum-based chemotherapy for non-small cell lung cancer patients: a meta-analysis of 24 studies. PloS One. 2013;8(11):e79864.

41. Chen YC, Tzeng CH, Chen PM, et al. Influence of GSTP1 I105V polymorphism on cumulative neuropathy and outcome of FOLFOX-4 treatment in Asian patients with colorectal carcinoma. Cancer Sci. 2010;101(2): $530-535$.

42. Voso MT, D’Alo F, Putzulu R, et al. Negative prognostic value of glutathione S-transferase (GSTM1 and GSTT1) deletions in adult acute myeloid leukemia. Blood. 2002;100(8):2703-2707.

43. Ekhart C, Rodenhuis S, Smits PH, Beijnen JH, Huitema AD. An overview of the relations between polymorphisms in drug metabolising enzymes and drug transporters and survival after cancer drug treatment. Cancer Treat Rev. 2009;35(1):18-31.

44. Tew KD. Glutathione-associated enzymes in anticancer drug resistance. Cancer Res. 1994;54(16):4313-4320.

45. Ishikawa T, Ali-Osman F. Glutathione-associated cis-diamminedichloroplatinum(II) metabolism and ATP-dependent efflux from leukemia cells. Molecular characterization of glutathione-platinum complex and its biological significance. J Biol Chem. 1993;268(27): 20116-20125. 


\section{Supplementary material}

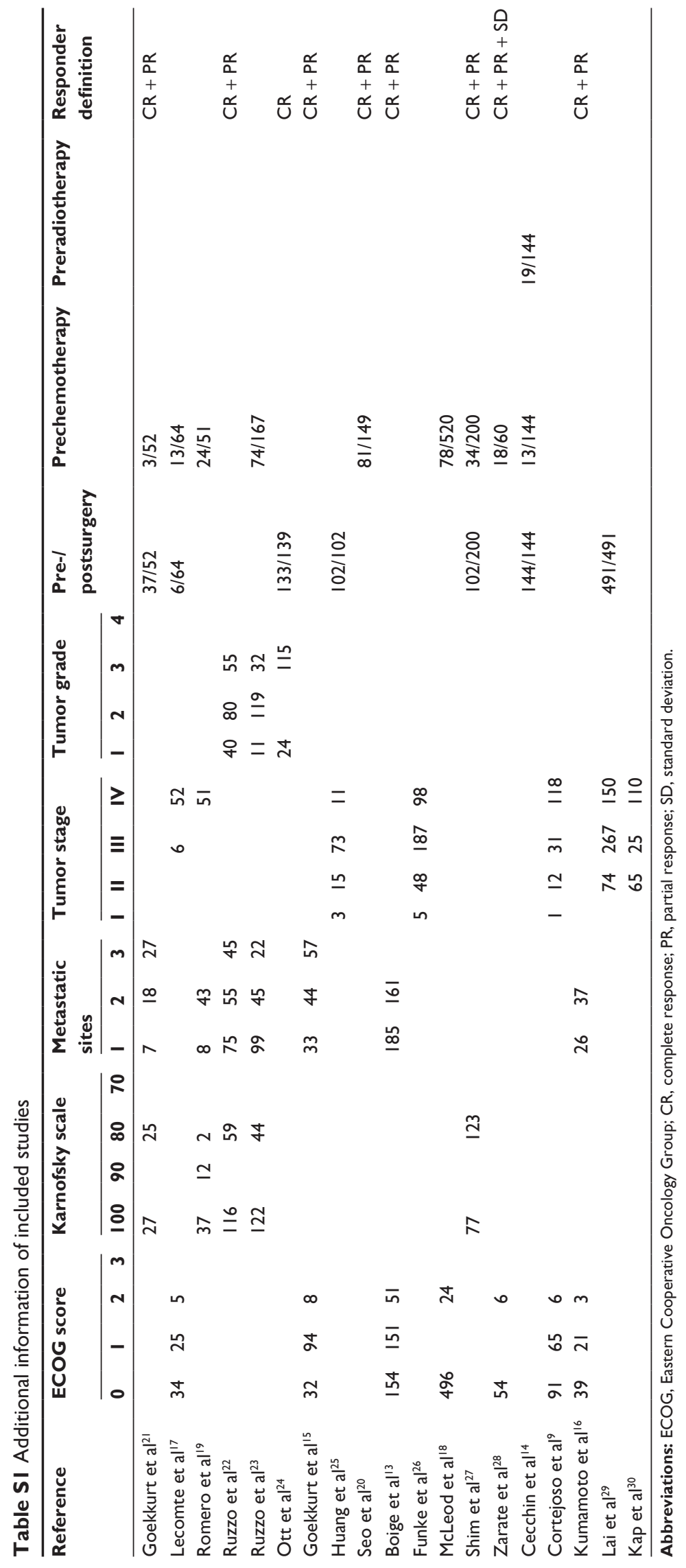




\section{Publish your work in this journal}

OncoTargets and Therapy is an international, peer-reviewed, open access journal focusing on the pathological basis of all cancers, potential targets for therapy and treatment protocols employed to improve the management of cancer patients. The journal also focuses on the impact of management programs and new therapeutic agents and protocols on

patient perspectives such as quality of life, adherence and satisfaction. The manuscript management system is completely online and includes a very quick and fair peer-review system, which is all easy to use. Visit http://www.dovepress.com/testimonials.php to read real quotes from published authors.

Submit your manuscript here: http://www.dovepress.com/oncotargets-and-therapy-journal 